\title{
The Economic Case for Pro-Poor Adaptation: What do we Know?
}

\author{
Tamsin Vernon
}

\begin{abstract}
1 Introduction
The world is already locked into climate change, regardless of our success at stabilising emissions. Under a best case mitigation scenario, temperatures will continue to rise until around 2050 (UNDP 2007). Developing countries will be among the most exposed, with the physical impacts disproportionately felt by poor and marginalised households and communities. Economic, social and environmental sensitivity to climatic conditions and poverty-driven low adaptive capacity compound their exposure and amplify existing challenges. Managing the inevitable impacts of climate change will therefore be critical in sustaining development achievements.
\end{abstract}

The objective of this article is to consider what we know, and still do not know, about the economic case for pro-poor adaptation, focusing on the following propositions:

- That adaptation is integral to and indivisible from development. Managing the impacts of a changing climate requires a greater shift towards climate-resilient development; and resilient economic growth is a key element of this, providing many of the opportunities and resources required for adaptation

- That households and communities will autonomously adapt but climate change risks undermine already overstretched coping strategies

- That well-functioning markets and a robust private sector are important drivers of adaptation in developing countries but will be constrained by market failures and other barriers

- That governments have an essential role in supporting pro-poor adaptation: deploying poverty-focused measures to help poor people avoid climate-driven poverty traps and addressing constraints that limit autonomous adaptation and provision of adaptation services by the private sector

- That those governments will have to make choices given budgetary constraints and the additional costs of climate-resilient development.

There are many other factors to be considered outside of this article, from the role of technology to the role of institutions. This article considers what needs to be done at a national level and by whom to ensure limited public resources deliver pro-poor adaptation in an efficient, effective and equitable manner.

\subsection{Pro-poor adaptation}

As it is a relatively new concept, there is no formally agreed definition of pro-poor adaptation. In the interim, the pro-poor growth agenda and its absolute and relative definitions can be instructive (Ravallion and Chen 2003; Ravallion 2004; Baulch and McCulloch 2000; Kakwani and Pernia 2000). Similar definitions could be assigned to pro-poor adaptation: actions that reduce the vulnerability of poor people to climate change, or actions that reduce the vulnerability of poor people faster than non-poor. This article will adopt an approach focusing on absolute rather than relative gains, on the basis that this is most useful to poor people who are most directly affected.

\section{What needs to be done: a shift in the development approach}

Adaptation is integral to and indivisible from development. Good development practice is the best way to deliver adaptation: increasing the resilience and capacity to manage the impacts of a changing climate. Educated, healthy people working in a diversified economy will be rendered less vulnerable overall and better able to deal with climatic shocks 
Figure 1 Climate-resilient development

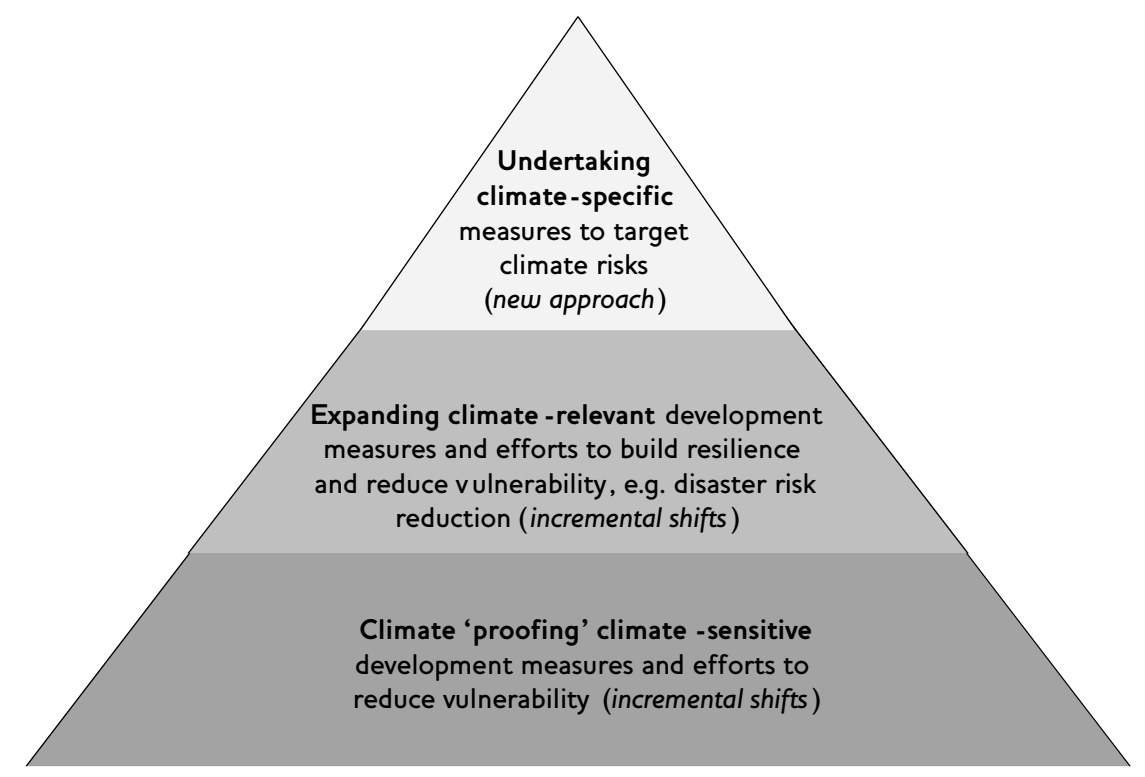

and change. Managing the impacts of a changing climate increases the need and urgency for development. But traditional development practice, in turn, requires adjusting to take account of the new, additional risks created by climate change.

In some areas, this will entail incremental shifts. For example, scaling-up efforts in climate-relevant areas such as irrigation and social protection schemes, and ensuring that climate-sensitive measures themselves take account of climate risks. This is important both to protect achievements from being undermined by climate impacts, but also to avoid inadvertently increasing long-term vulnerability to climate change, 'maladaptation'; for example clearing mangroves (a natural coastal defence) to make way for tourism. In others, it will also entail undertaking entirely new measures that were not necessary under past or current climate conditions. This may range from reducing risks of climate-induced glacial lake outburst floods to modelling climate change and its impacts.

Together, these adjustments represent a shift towards climate-resilient development, characterised in Figure 1. Different countries will have to make different adjustments determined by both their needs (adaptation being location specific) and resources.

\subsection{The critical role of climate-resilient economic growth}

Economic growth is an essential driver of climateresilient development. It is recognised by many as one of the most powerful defences against poverty, a core barrier to adaptation (Collier 2007). For example,

Dollar and Kraay (2001) found over 80 per cent of the reduction in poverty achieved since 1985 to have been achieved through growth, with less than 20 per cent a result of changes in inequality. ${ }^{1}$ Growth provides people with the livelihood opportunities and resources with which to build up their adaptive capacity and better manage risks. It enables governments to mobilise domestic revenue from a broadening tax base to fund essential public services from health and education services that enhance people's prospects for employment and economic advancement, to climate proofing and expanding climate-sensitive and relevant activities and investing in climate-specific measures such as responding to glacial melting. There is much evidence that growth benefits poor people on average as much as everyone else in society, although this does not imply that growth is all that is required to improve the lives of the poor (Dollar and Kraay 2001).

Climate-resilient growth-enhancing policies should therefore be a core element of a pro-poor adaptation strategy. This is in recognition that 
economic growth is itself exposed to climate change impacts. In Mozambique, for example, where water infrastructure is undeveloped and irrigation use limited, GDP growth rates are on average reduced by at least 1.1 percentage points annually due to sensitivity to water shocks (floods and droughts) (World Bank 2005). Climate change can impact growth in the short term by a loss of assets and revenue sources (e.g. the La Nina drought in Kenya caused damage in the order of 16 per cent of GDP in each of 1998-99 and 1999-2000 financial years (World Bank 2006), and over the longer term by a worsening fiscal situation. For example, governments switching expenditure from longer-term investments such as education to shorter-term reconstruction needs or, where it is available, increasing debt levels to meet climate costs and consequences.

Climate-resilient growth again entails incremental shifts to traditional approaches including, for example, making public infrastructure investments climate resilient. This is critical given planned levels of infrastructure investment in developing countries, and an opportunity to avoid the significant retrofitting costs facing developed countries. But new measures and approaches to growth may also be necessary. This may include shifting economic activity into entirely new sectors or significant diversification. For example, given key fish species are likely to migrate with rising water temperatures, the Namibian commercial fish processing sector will need to consider diversifying to other activities rather than increasing long-term investments in this sector, which presently represents almost one-third of the country's exports (UNDP 2007). Future planning is essential in order to identify potential activities that will be resilient in a changing climate and where there is scope to develop new comparative advantages. It is also important to ensure that any shifts take account of future carbon constraints, both to ensure that future exports are competitive in an increasingly carbon constrained world, and to avoid shifting to an economic strategy that locks in a high carbon footprint that could constrain a country's future growth prospects.

3 Who needs to do what: the role of individuals, households and communities

Individuals, households and communities are

predominantly responsible for managing the risks they face from climate change (Tanner and Mitchell, this IDS Bulletin, 'Entrenchment or Enhancement'; Prowse and
Scott, this IDS Bulletin). They will typically have the best information about their own specific situation and risks they face. They have existing indigenous knowledge and skills from dealing with past and current climate variability. And they have strong incentives to act to protect and sustain their livelihoods.

Indeed, people have been developing effective coping strategies to manage natural climate variability for centuries. For example, villagers in Attapeu Province, Lao PDR, switch from farming to fishing during August-October when floods typically occur. In addition to ensuring their livelihoods are sustainable, this is a beneficial coping mechanism as it diversifies their predominantly rice-based diet and increases vitamin and protein intake (UNFCCC database 2008). Recognising the important role of local coping strategies, the UN Framework Convention on Climate Change (UNFCCC) has compiled a database of experiences. This can facilitate the transfer of long-standing coping strategies and mechanisms, knowledge and experience from communities who have already been adapting to (naturally) changing climatic conditions to communities that are newly exposed. This ranges from lessons from community reforestation in Rio de Janeiro to the experience of peasant farmers using plant extracts to exterminate cattle ticks in Ethiopia. ${ }^{2}$

\subsection{Constraints and poverty traps}

Climate change however, risks overstretching already strained coping strategies as households face new threats and/or more frequent and intense climatic events. Strategies that have been effective over centuries may become insufficient or ineffective. For example, many traditional risk-sharing mechanisms based on social capital such as asset pooling and kinship networks will be less effective when climate change simultaneously affects families and households in an entire region (as echoed in Prowse and Scott, this IDS Bulletin).

Coupled with this, people will not always undertake optional levels of autonomous adaptation due to market failures and barriers that create disincentives to adapt or inability to access the right adaptation knowledge and tools. For example, institutional constraints such as lack of property rights or civil protection may prevent poor people from investing their scarce resources in managing climate risks; for example not making their property climate resilient due to fear that the authorities will evict them once 
the work is complete (IFRC 2004). Or lack of economy-wide resilience (e.g. non- 'climate-proofed' public infrastructure) may prevent poor households from reaping the benefits of their adaptation efforts. For example, a Nepalese family were able to manage the impacts of floods by successfully diversifying their farming livelihood to include fisheries but were unable to sell their produce as the muddy road from Taratal to Sanoshree market was flooded (Mitchell et al. 2007). Or, limited access to climate information and tools may prevent people from being able to adapt effectively (e.g. where new climate-resilient seed varieties are not reaching rural areas).

Very poor and marginalised people (e.g. some women, children, pastoralists, disabled people, or indigenous people) face further barriers that limit their ability to adapt. In addition to the above constraints, they face economic, cultural and institutional barriers that can prevent them from accessing the adaptation tools and resources that growth and the private sector (discussed below) can provide. For example restricted land rights due to institutional constraints make it difficult for women in many developing countries to access credit; elderly women may lack access to and knowledge of private sector health services; cultural constraints limit girls' access to education with which to enhance their future economic opportunities; and a lack of voice and influence in decision-making processes results in community adaptation strategies or government policies being less likely to address their specific needs (as discussed in Demetriades and Esplen, this IDS Bulletin; Polack, this IDS Bulletin).

Together these constraints limit the options for and ability of poor people to adapt to climate change. In the worst case scenario, they may be forced to adopt extreme coping - or survival - strategies (in particular very poor and marginalised people). In the absence of savings, access to credit, or insurance, for example, households may sell off their productive assets on which their recovery depends. The costs of this action are magnified by the low price they will likely get for their asset, as others adopt similar coping responses. For example distressed sales of livestock in Ethiopia following the drought in 1999 sold for 50 per cent less than the normal price (Carter et al. 2004). Similarly, households may have little choice but to reduce their nutritional consumption or take their children out of school, thus undermining their long-term human capital and earning potential. These survival strategies risk pushing people further below the poverty line and new people into poverty traps (as with extreme climate variability today).

If poor individuals, households and communities are to be able to manage the risks they face from climate change, government support will be required to help them overcome constraints and barriers, such as those listed above. Poverty-focused measures will need to be deployed, such as social safety nets and livelihood diversification to help poor households manage the risks of climate change. Governments can also play an important role in enabling the private sector to provide vital adaptation services for poor people, as will be discussed below.

\section{Who needs to do what: the role of markets and the private sector}

The private sector is a typically overlooked implementer and driver of adaptation. Much of the climate finance discussion, for example, is around the need for the public sector (national/international) to meet the additional costs of adaptation. However, not only will it be impossible for the public sector to undertake this alone given the scale of efforts required but, in ignoring the role of the private sector, public finance risks replacing investments that the private sector may have voluntarily undertaken in order to manage their own climate exposure. Motivated by the need to protect their profits, the private sector, from the small village farmers described above to large multinational corporations investing in developing countries, will have an incentive to adapt.

The private sector can also help poor households and communities to build their overall resilience and undertake effective coping strategies, as described above, especially those with access to markets in developing countries. For example:

- Contributing to government tax base and the public services this can support (as set out above)

- Providing essential elements of poor peoples' adaptive capacity, including incomes through the jobs they create, technical inputs through the goods they produce (e.g. fertiliser) and risk management tools through the services they provide (e.g. finance)

- Raising awareness and incentivising climate risk management behaviour among poor people 
through price signals they set through insurance premiums or loan conditions

- Generating and delivering many of the new investments and instruments required to manage a changing climate, from new technologies (e.g. drought-resistant crops) to climate protection infrastructure (e.g. flood defences)

- Directly supporting the adaptive capacity of local communities in order to improve their business performance and risk management (e.g. to increase employee productivity or support an improved operating environment)

- Incentivising governments to address climate change risks where these threaten economic competitiveness, for example an unreliable water supply or access to ports provides disincentives for investments, in turn benefiting poor people who also use this infrastructure.

These adaptation benefits will be driven by international investors and banks through to smalland medium-sized firms operating in developing countries. There is already evidence of the private sector helping to build the resilience of poor people. For example, the owners of an aluminium smelter project in Mozambique participated in a malaria control programme to protect the success of their project. ${ }^{3}$ There has subsequently been a decline from 85 per cent of children who lived near the smelter being infected in 1999, to 20 per cent by June 2005. Similarly, in Bangladesh, poor households reduce their vulnerability to natural disasters by using financial services to accumulate savings (Ferrand et al. 2004). These actions, while not undertaken to address climate change risks specifically, contribute to building adaptive capacity of poor people.

\subsection{Market failures and constraints}

While the private sector will be motivated to carry out some autonomous adaptation efforts, pervasive market failures and other barriers will prevent them from undertaking socially optimal levels of investment (as with individuals, households and communities described above). This is both with regard to their own autonomous adaptation and the provision of adaptation services for poor people. This is driven by factors including:

- Uncertainty and lack of climate information or awareness that deters private actors from ensuring their businesses or livelihoods are climate resilient
- Competitiveness concerns that can create a disincentive to adapt where this imposes an additional cost and climate impacts are not certain. For example, the engineering costs of a building designed to withstand rising temperatures and extremes will typically be greater than that of a standard property and if property buyers do not discriminate between properties on the basis of vulnerability to future climate (due to lack of information), the standard property will be more competitive.

- Inability to capture the full benefits of private actions that generate wider public benefits (e.g. flood defences), in turn encouraging underinvestment in adaptation

- Financial constraints that prevent sufficient investments being made

- Shorter-term drivers that dominate private actors' decision-making.

If the private sector is to help drive adaptation in developing countries, governments will need to intervene to provide the necessary tools and incentives for them to adapt and help to overcome current barriers to adaptation.

\section{Who needs to do what: the role of government}

Governments have a pivotal role in supporting propoor adaptation. Recalling the need for a shift in the development approach, a critical first step is ensuring that adaptation is integrated into and across national development plans and budgets, as described above. But the government's role expands beyond this. They can also play a critical function in delivering povertyfocused measures and providing poor individuals, households and communities with the right incentives, tools and capacity to adapt; and addressing the market failures and barriers that constrain autonomous adaptation and provision of pro-poor adaptation services by the private sector.

\subsection{Supporting autonomous adaptation by} individuals, households and communities Government support is required in providing poverty-focused measures that provide poor people with a wider range of options and opportunities for managing climate risks. This includes measures to help them build their general resilience and move into productive livelihoods but also to better manage climate specific risks. This is particularly important given that climate change is predicted to lead to an increase in both frequency and intensity of climatic 
shocks, and the risk of cumulative impacts puts increased pressure on already overstretched coping strategies.

Traditional development tools can be applied to manage these risks, from providing access to microcredit and social insurance, to providing social protection schemes and asset transfers. In Mexico, for example, transfers are provided conditional on parents keeping their children in school and undertaking periodic health checks. The programme has resulted in a 23 per cent reduction in the probability that children will leave school in the event of drought or other shocks (UNDP 2007). A core element to this strategy should be to support poor and marginalised people in building up their assets which, in providing them with the opportunities and resources to build their overall resilience, are central to increasing their adaptive capacity (as recognised in Prowse and Scott, this IDS Bulletin). Coupled with this, governments need to ensure that households are able to maximise their returns from these assets and livelihood opportunities, for example by providing secure property rights and ensuring reliable access to markets, as discussed above.

But these measures also need to be adjusted to take account of the changing climate. More resources may have to be allocated to these poverty-focused measures as the number of people exposed to climate risks and shocks increases. And traditional measures will need to be screened for climate risks as the exposure that people face is changing, from increased frequency and intensity of extreme weather events to exposure to entirely new threats of which people have no prior experience (e.g. shifts in malaria epidemics). This is also necessary in considering the longer-term effects of these policies. For example, providing poor people with social insurance will help them to manage risks without having to run down their assets or reduce consumption. However, at the same time it is important that this insurance does not encourage people to stay in activities or locations that may no longer be sustainable in light of climate change (as the price signal that indicates rising risks is hidden by government subsidies). Similarly, micro-credit schemes need to ensure climate risks are factored into loan agreements to ensure they are able to support resilience and not lead to increased vulnerability (e.g. if loans are used to purchase land that will not have access to water in five years).
These changes represent 'incremental shifts' to traditional development approaches, as discussed above. In some cases, new policy instruments may also be required that were not relevant or a priority previously - for example health awareness campaigns and mobile health units that provide malaria assistance in areas previously unexposed. In undertaking both incremental shifts and new approaches to development, it is important to recognise that poor people typically have high discount rates, reflecting their focus on their wellbeing (or survival) today. This creates complications with the longer-term planning and investment required for adaptation, which these measures should help to overcome.

\subsection{Supporting autonomous adaptation and provision of adaptation services by the private sector}

Identifying ways to foster and leverage private sector engagement on adaptation and market-driven adaptation opportunities is also an important element of a government's pro-poor adaptation strategy (OECD 2008). Stimulating the private sector both to address their own climate risks and to deliver adaptation services (from investing in new technologies to providing insurance products) frees up public resources that may otherwise have had to be deployed to provide this support. It also helps in protecting and generating public funds (from a growing tax base), which can be used to deliver poverty-focused measures to poor and marginalised people who are most dependent on public assistance and may not be serviced by the markets.

An important role for governments can include helping the private sector overcome information constraints that deters them from taking action. In part, this entails investing in and communicating climate information. Improved climate information enables people to make rational and effective adaptation decisions, helps ensure climate risks are properly priced in the market and can encourage adaptation-specific investments such as insurance. ${ }^{4}$ But even improved information will not necessarily narrow projection ranges and therefore levels of uncertainty will likely remain high. For example, there are still large differences between models in how they treat climate sensitivity despite improved understanding of climate processes (Hallegatte 2008). Governments therefore have an important role in helping to overcome this residual uncertainty. 
Setting long, loud and legal signals will also help stimulate adaptation efforts by the private sector. Compulsory regulations and performance standards can help address this uncertainty barrier and overcome competitiveness constraints, for example if all buildings have to be built to a more resilient standard. Credible enforcement systems are required, however, for these measures to be effective. Regulations can over-specify the risks, imposing higher costs than necessary on the private sector, as governments face the same climate uncertainties as the private sector. These are the risks that governments will need to weigh up in assessing the benefits and costs of different policies, considering also the risks of significant retrofitting costs or irreversible impacts if action is delayed.

Credible signals that governments will not bail out companies that do not take climate risks into consideration is also a strong motivational factor for action, and helps avoid risks of moral hazard. Finally, the important role of the private sector in supporting adaptation further reinforces the need for governments to create a good enabling environment to attract and retain private sector investment. Given climate risks, however, this must also include a credible adaptation strategy, as described above, to overcome the threat of climate change becoming a disincentive to invest.

\section{Making choices with budgetary constraints}

Shifting to climate-resilient development will entail an additional cost - as well as benefits - at all levels of the economy. Governments have limited public resources with which to deliver on a wide range of competing priorities, including adaptation. While increased international funding will help to reduce this budget constraint, it will still be limited. Governments will therefore need to consider how best to allocate limited public investment resources in the face of competing demands: between different economic sectors and activities, different social groups and needs, and between different adaptation measures.

\subsection{Additional costs of adaptation}

There are two drivers for understanding the cost of pro-poor adaptation: to identify what combination of measures generates the maximum returns given binding budget constraints, and to be able to include the necessary budget within expenditure plans. In some circumstances, the costs will be minimal and may even generate revenue or lead to cost savings in the longer term (such as improving water efficiency). It is important to note, however, that even where adaptation may be cost-neutral or -positive, there may be transitional costs involved that must be managed. ${ }^{5}$ In other cases the costs may be significant, whether it is expanding current development priorities relative to plans today (e.g. irrigation), making these investments climate resilient, and/or investing in new targeted measures.

These additional costs are still very uncertain, and will vary considerably between regions and sectors. The available analysis tends to focus on global adaptation costs, with guesstimates putting the bill in the range of tens of billions of dollars per annum. ${ }^{6}$ These numbers are helpful in making the case for additional international support, but less helpful in prioritising climate-resilient choices or understanding the additional budget requirements at the national level.

Significantly more work is required to better understand the costs involved in implementing climateresilient national development plans. One complication in this exercise, in particular given its link to international financing negotiations, is how to measure the additional costs without creating perverse incentives to focus exclusively on climate-specific measures (the top of the pyramid in Figure 1). The specific adaptation benefits of 'new approaches' are more clearly measurable than the 'incremental shifts' and therefore 'additionality' to development easier to prove. However, an exclusive focus on these measures is not the most effective way to adapt (either in terms of cost or the resilience generated). More analysis is also required to measure and quantify the benefits and costs of softer adaptation measures, such as changing regulations, institutions and, consequently, behaviour. The UK Department for International Development (DFID), together with the Netherlands Ministry of Foreign Affairs, is funding a research study with the World Bank to better understand the benefits and costs of adaptation in developing countries.

\subsection{Benefits and costs}

Understanding the benefits and costs of different measures to build climate resilience is essential in order to identify the most cost-effective adaptation approaches. It also facilitates prioritising the most effective strategies at national, sectoral and local levels without increasing distributional inequalities, 
poverty indices and vulnerability among different income groups and communities. However, there are complications to this approach that need to be considered:

- Difficulty in assigning monetary values to social and environmental benefits and costs. If these factors cannot be incorporated into governments' decision framework, adaptation priorities will always be skewed in favour of economic costing criteria.

- Inadequate timescales. For example, the financial costs of social protection schemes will be met in a relatively concentrated period. If decisionmakers only compare the benefits accrued over this short period they will ignore the avoided long-term impacts on poor people's growth potential. This accrues over many years and to all levels of the economy through improved economic opportunities and higher productivity levels and reduced long-term welfare expenditure.

- Transitional costs. For example, government action in Rwanda to tackle a rising energy (hydropower) crisis had a positive net adaptation impact (e.g. increased rural electrification programmes) but incurred short-term costs on local communities that were no longer able to use the now protected wetlands and lakeshores as supplementary farming plots. These costs need to be recognised and support provided to help these communities diversify and enhance their livelihoods (UNDP 2007).

\section{Conclusions and recommendations}

This article has focused on key elements of what we know about the economic case for pro-poor adaptation - what this should entail and by whom. In the process, areas that require further analysis are identified and captured below.

First, that adaptation entails a shift from traditional development to climate-resilient development. It is critical that adaptation is treated as integral to development, rather than a standalone and separate activity. However, exactly what mix of incremental shifts and new approaches are required for 'optimal' adaptation will be country specific. More bottom-up analysis is needed to understand how best to adjust national development strategies to be climate resilient.

Second, just as growth plays a central role in poverty reduction, so it is an essential element of any pro- poor adaptation strategy. It equips people with the opportunities and resources with which to build their adaptive capacity. But growth is also vulnerable to the impacts of climate change. Ensuring economic growth strategies and achievements are themselves climate resilient must therefore be a priority in any adaptation strategy. Little research has been done to date on the sensitivity of economic growth to climate change, although the disaster risk reduction literature can be instructive. Understanding these sensitivities and where and how to increase resilience in a manner that builds the long-term competitiveness of economies is essential.

Third, that individuals, households and local communities will undertake a significant amount of autonomous adaptation, as they have been doing for centuries. However, these existing strategies may become ineffective and, in some cases, increase their long-term vulnerability due to a combination of increased risks from climate change and constraints and barriers that restrict the scope and incentives for autonomous adaptation. Governments have a vital role therefore in helping people to overcome these barriers and deliver poverty-focused support. More analysis is needed to better understand the human impacts of climate change and transmission mechanisms. In turn, this should help inform effective climate-resilient poverty-focused measures.

Fourth, that the private sector in developing countries will also undertake significant levels of autonomous adaptation and, together with wellfunctioning markets, could play an important role in helping to build adaptive capacity of poor people. However, this has received minimal attention to date. Much more analysis is needed to understand the potential scope and scale of private sector engagement, how this can be stimulated and leveraged with public sector support, and what the barriers may be that prevent the private sector playing this function.

Finally, it is clear that governments can play a pivotal role in supporting pro-poor adaptation. From ensuring national development and growth strategies are climate resilient, to delivering povertyfocused support to poor and marginalised people and providing the right tools and incentives for the private sector to adapt and deliver adaptation services. While these measures clearly generate benefits (avoided impacts) they also have a cost. And 
even with additional international support national budgets will have limits.

Governments (and the wider international community) therefore need a better understanding of the benefits and costs of adaptation, both to be able to better prioritise between measures (with cost as one of several determining criteria) and to budget for adaptation. More analysis is therefore required on understanding the expenditure requirements of climate-resilient development plans. As an important element of this, further work is also required on valuing ecosystem services and work in the unpaid

\section{Notes}

1 This is in terms of reducing the number of people living on less than $\$ 1$ a day. There is wide agreement in academia based on empirical evidence that growth is the most important factor in poverty reduction.

2 http://maindb.unfccc.int/public/adaptation/ (accessed 11 July 2008)

3 They identified malaria as a business risk affecting the facility's productivity through its impacts on workers and their families that lead to absenteeism and low staff morale, and becoming a less attractive destination for skilled employees (Acclimatise 2008).

\section{References}

Acclimatise (2008) 'Credit Risk Impacts of a Changing Climate: Co-benefits for Improved Community Adaptive Capacity', draft, commissioned by DFID

Baulch, R. and McCulloch, N. (2000) 'Tracking Propoor Growth', ID21 Insights 31, Brighton: IDS

Carter, M.R.; Little, P.D.; Mogues, T. and Negatu, W. (2004) Shock, Sensitivity and Resilience: Tracking the Economic Impacts of Environmental Disaster on Assets in Ethiopia and Honduras, Wisconsin: BASIS

Collier, P. (2007) The Bottom Billion: Why the Poorest Countries are Failing and What Can be Done About it?, Oxford: Oxford University Press

Dollar, D. and Kraay, A. (2001) Growth is Good for the Poor, Policy and Research, Working Paper, Washington DC: World Bank

Ferrand, D.; Gibson, A. and Scott, H. (2004) Making Markets Work for the Poor: An Objective and an Approach for Governments and Development Agencies, Pretoria: ComMark Trust economy, and on what equity weights to assign to different social groups in prioritising between adaptation measures.

More knowledge is needed on all these elements if we are to better understand and progress in integrating robust, pro-poor adaptation strategies into long-term development plans and budgets in a context of high uncertainty, potentially high future costs, and competing needs. This will require concerted efforts by national governments and research institutions, through to the international community.

4 In the absence of this information, businesses may be unwilling to invest, e.g. in risk mapping in case

(a) the market does not prove to be viable, or (b) others can benefit from this information.

5 For example, by removing water subsidies in order to improve efficiency in the way this resource is used, a critical element of this adaptation response is ensuring that poor people have access to this essential resource.

6 For example, the World Bank, Oxfam, UNDP and the UNFCCC Secretariat.

Hallegatte, S. (2008) Adaptation to Climate Change: Do Not Count on Climate Scientists to Do Your Work, Washington DC: Reg-Markets Center

IFRC (2004) World Disasters Report 2004, Geneva: International Federation of the Red Cross and Red Crescent Societies

Kakwani, Nanak and Pernia, E. (2000) 'What Is ProPoor Growth?', Asian Development Review 18.1: 1-16

Mitchell, T.; Tanner, T. and Lussier, K. (2007) We Know What we Need: South Asian Women Speak Out on Climate Change Adaptation, London: IDS/Action Aid

OECD (2008) Economic Aspects of Adaptation to Climate Change: Costs, Benefits and Policy Instruments, Paris: Organisation for Economic Co-operation and Development

Ravallion, M. (2004) Pro-poor Growth: A Primer, Washington DC: Development Research Group, World Bank

Ravallion, M. and Chen, S. (2003) 'Measuring ProPoor Growth', Economics Letters 78.1: 93-9 
UNDP (2007) Human Development Report 2007/2008 Fighting Climate Change: Human Solidarity in a Divided World, New York: United Nations Development Programme

UNFCCC Database on Local Coping Strategies, http://maindb.unfccc.int/public/adaptation/ (accessed 10 July 2008)
World Bank (2006) Managing Water Resources to Maximise Sustainable Growth: A Country Water Resources Assistance Strategy for Ethiopia, Washington DC: World Bank

World Bank (2005) 'Role of Water in the Mozambique Economy', World Bank Memorandum, AFTU1, Washington DC: World Bank 